\title{
Aspectos gametogênicos e histoquímicos de Iphigenia brasiliana (Lamarck) (Bivalvia, Donacidae) da Lagoa de Itaipu, Niterói, Rio de Janeiro, Brasil
}

\author{
Eliana de Fátima Marques de Mesquita ${ }^{1,2}$ \\ Marta Guimarães de Abreu ${ }^{3}$ \\ Francisco Carlos de Lima ${ }^{1}$
}

\begin{abstract}
Gametogenic and histochemical aspects of edible bivalve Iphigenia brasiliana (Lamarck) (Bivalvia, Donacidae) from the Itaipu lagoon, Niterói, Rio de Janeiro, Brazil. Gametogenic and histochemical aspects of an edible bivalve, Iphigenia brasiliana (Lamarck, 1818) from Itaipu Lagoon, Niterói, State of Rio de Janeiro, were studied. Between May 1998 and October 1999 a total of 120 clams were picked up. Samples of 10 animals were collected once a month. Specimens were fixed in Bouin's fixative for 4 hours or less and transferred to $10 \%$ formalin for 24 hours. The shell lenght has been measured with the valves lightly opened to permit the penetration of fixative solution deeply in the tissues. Transverse sections including digestive diverticula, mantle, gills, gonad and foot were obtained fiom the total body. After fixative treatment, tissues sections were embedded in paraffin, cut routinely at $5 \mu \mathrm{m}$ and stained with Harris's hematoxylin and eosin. Microscopic analysis was carried out at low and high dry magnifications, as well as under oil immersion. Advanced ova stages were measured. Special staining techniques have been applied as a tentative tool for searching glycogen, mucous cells, collagenic and reticulin fibers, RNA and protozoan organisms. The animals collected showed variation in lenght from $7.20 \mathrm{~cm}$ to $4.10 \mathrm{~cm}$ and in height from $4.60 \mathrm{~cm}$ to $3.10 \mathrm{~cm}$. The sex ratio (M:F) was 40:69. The average ova diameter of I. brasiliana was $34.70 \mu \mathrm{m}$ with a standard deviation of $5.19 \mu \mathrm{m}$. Nothing could be observed in I. brasiliana, concerning to lesions and parasites at histopathological analysis.

KEY WORDS. Gametogenic cycle, histology, special-staining methods, Iphigenia brasiliana, Itaipu Lagoon, Brazil
\end{abstract}

Iphigenia brasiliana (Lamarck, 1818) é encontada enterrada aproximadamente a até $15 \mathrm{~cm}$ de profundidade, no fundo areno-argiloso ou lodoso de baías e enseadas. Seu nome vulgar é "tarioba", segundo Boffi (1979). No Brasil, atinge os Estados do Paraná e de Santa Catarina (GofFerJé 1950) e São Paulo e Rio de Janeiro (LANGe DE MorRetes 1949). Na Lagoa de Itaipu é denominada de "taioba" e é consumida não só pela população local, como também por alguns cidadãos da colônia nipônica para o preparo de sopas e outros pratos orientais.

Na espécie estudada, as gônadas ocupam o espaço entre as regiões do canal alimentar na massa visceral, não se estendendo para o manto. As aberturas genitais ficam na superfície posterior dorsal da massa visceral, abaixo do nefrídio e abrem-se

1) Departamento de Tecnologia de Alimentos, Universidade Federal Fluminense. Rua Dr. Vital Brazil Filho 64, 24230-340 Niterói, Rio de Janeiro, Brasil. E-mail: eliana@esquadro.com.br

2) Bolsista do CNPq.

3) Bolsista de Iniciação Cientifica da FAPERJ/UFF

Revta bras. Zool. 18 (2): 523 - 528, 2001 
no espaço epibranquial sobre a demibrânquia interna. NARCHI (1972) examinou espécimes de $I$. brasiliana entre maio a outubro e verificou que um certo número de fềmeas estava, aparentemente, maduro. CoE (1943) referiu algumas espécies do gênero como hermafroditas, mas não as citou textualmente.

Durante os fenômenos de gametogênese ocorre variação muito grande na quantidade de glicogênio e lipídios presentes nas gônadas e vários são os fatores que interferem na maturação sexual, entre os quais estão: a temperatura, a salinidade e o alimento disponível.

Estudos futuros do ciclo sexual desta espécie se fazem necessários para a comprovação do fato de serem unissexuais, sexuais consecutivas ou sexuais alternadas, conforme a classificação de $\operatorname{CoE}$ (1943). A coleta indiscriminada dos bivalves comestíveis poderá acarretar como conseqüência o perigo da extinção de reservas naturais e seria desejável obter o maior número possível de dados de modo a estabelecer diretrizes que tenham como preocupação não apenas manter as referidas reservas, como propiciar o povoamento de regiões onde os animais não ocorram e talvez, no futuro, repovoar áreas onde eles não mais se encontram.

\section{MATERIAL E MÉTODOS}

Para a pesquisa foram utilizados cento e vinte exemplares de $I$. brasiliana com coletas mensais de dez animais na lagoa de Itaipu junto ao canal de Camboinhas, Niterói, Rio de Janeiro ( $22^{\circ} 58^{\prime} \mathrm{S}, 43^{\circ} 02^{\prime} \mathrm{W}$ ) perfazendo uma série de doze coletas. A primeira coleta foi realizada em maio de 1998 e finalizada na segunda quinzena de outubro de 1999.

Os animais foram coletados manualmente a cerca de $20 \mathrm{~cm}$ de profundidade em fundo areno-lodoso.

Espécimes vivos destes venerídeos foram acondicionados em recipientes limpos e isotérmicos, mantidos em água oriunda do ambiente natural e de preferência a baixas temperaturas (resfriada), quando em períodos de elevada temperatura ambiente. A fixação foi realizada o mais breve possível, após a coleta, para reduzir modificações fisiológicas ou postmortem.

Os exemplares foram fixados, ainda dentro das conchas, porém com as valvas entreabertas, em Bouin por até quatro horas e transferidos para formol a $10 \%$ por 24 horas. As valvas foram medidas e as partes moles removidas. Foi efetuada a secção transversal, incluindo divertículo digestivo, manto, brânquias, gônada e pé. Depois de desidratados, os tecidos foram embebidos em parafina, seccionados a $5 \mu \mathrm{m}$ e corados pela hematoxilina-eosina. Procedeu-se a análise microscópica e medição dos oócitos em estádios avançados. Técnicas especiais de coloração foram aplicadas para evidenciação de glicogênio, células mucíparas, fibras colagênicas, fibras reticulares e protozoários (HowARD \& SMITH 1983). Os métodos histoquímicos utilizados neste trabalho foram: PAS, DPAS, van Gieson e Giemsa.

Procedeu-se a análise das lâminas coradas com HE determinando-se o sexo e o estádio de desenvolvimento gonadal, baseando-se em NARCHI (1976) e POWELL et al. (1993). Ao mesmo tempo, foi realizado o exame histopatológico com vista à observação de parasitas e lesões. 
Estádios avançados dos oócitos da espécie I. brasiliana foram medidos a partir do estádio 5, segundo Powell et al. (1993).

\section{RESULTADOS E DISCUSSÃO}

Os animais da espécie $I$. brasiliana coletados na Lagoa de Itaipu apresentaram variação de tamanho de: 7,2 a 4,1 cm de comprimento e de 4,6 a 1,3 cm de largura.

O sex-ratio (M:F) encontrado foi de 40:69. Em quase todas as coletas realizadas a proporção de macho e fềmea demonstrou que as fêmeas estão em maior número na natureza. NARCHI (1972) examinou espécimes de I. brasiliana entre maio a outubro, em Santos, Caraguatatuba, Ubatuba - São Paulo, e verificou que um certo número de fêmeas estava aparentemente maduro. No entanto, referiu que não foi achado nenhum espécime macho. Neste estudo, preferiu-se seguir a classificação do desenvolvimento gonadal de Powell et al. (1993), que abrange os estádios de 1 a 8. Na presente pesquisa, não foi observado o estádio 1 nos machos, nem o estádio 8 em ambos os sexos (Tab. I). De acordo com o exposto, o período de gametogênese tanto para machos quanto para fêmeas corresponderia aos meses quentes do ano.

Tabela I. Percentagem dos diferentes estádios gonadais em machos e fêmeas de Iphigenia brasiliana.

\begin{tabular}{|c|c|c|c|c|c|c|c|c|}
\hline \multirow{2}{*}{ Mês/Ano } & \multicolumn{4}{|c|}{ Fèmeas (\%) } & \multicolumn{4}{|c|}{ Machos (\%) } \\
\hline & 1 & 2 a 3 & 4 a 5 & 6 a 7 & 1 & 2 a 3 & 4 a 5 & 6 a7 \\
\hline Mai/98 & 0 & 0 & 100 & 0 & 0 & 100 & 0 & 0 \\
\hline Jun/98 & 0 & 100 & 0 & 0 & 0 & 100 & 0 & 0 \\
\hline $\mathrm{Jul} / 98$ & 25 & 75 & 0 & 0 & 0 & 100 & 0 & 0 \\
\hline Ago/98 & 0 & 100 & 0 & 0 & 0 & 100 & 0 & 0 \\
\hline Set/98 & 0 & 66 & 33 & 0 & 0 & 100 & 0 & 0 \\
\hline Out/98 & 0 & 80 & 20 & 0 & 0 & 80 & 20 & 0 \\
\hline Nov/98 & 0 & 75 & 25 & 0 & 0 & 50 & 50 & 0 \\
\hline Dez/98 & 0 & 0 & 100 & 0 & 0 & 100 & 0 & 0 \\
\hline Jan/99 & 0 & 0 & 100 & 0 & 0 & 0 & 75 & 25 \\
\hline Fev/99 & 0 & 0 & 63 & 37 & 0 & 0 & 0 & 100 \\
\hline Mar/99 & 0 & 0 & 75 & 25 & 0 & 0 & 0 & 100 \\
\hline $\mathrm{Abr} / 99$ & 0 & 0 & 50 & 50 & 0 & 0 & 0 & 100 \\
\hline
\end{tabular}

As percentagens dos estádios gonadais 6 e 7 encontradas em I. brasiliana (Fig. 1), distribuíram-se nos meses de fevereiro, março, abril de 1999 (37\%, 100\% e $50 \%$, respectivamente) nas fềmeas. No caso dos machos (Fig. 2), estas percentagens apresentaram-se bem maiores e acompanharam os meses de janeiro, fevereiro, março e abril de 1999 (25\%, 100\%, 100\% e 100\%, respectivamente). Nos cortes histológicos dos ovários, o estádio sexual mais desenvolvido (estádio 7) encontrado caracterizava-se pela presença de oócitos maduros e em número reduzido (Fig. 3).

A tabela II mostra os diâmetros e respectivas médias para os estádios mais avançados dos oócitos. A média total foi de $34,70 \mu \mathrm{m}$, sendo o desvio padrão de $5,19 \mu \mathrm{m}$.

Ao exame microscópico não foram observados parasitos ou lesões na espécie em estudo. Provavelmente, I. brasiliana possui maior resistência aos parasitos comumente encontrados em outros bivalves comestíveis. 

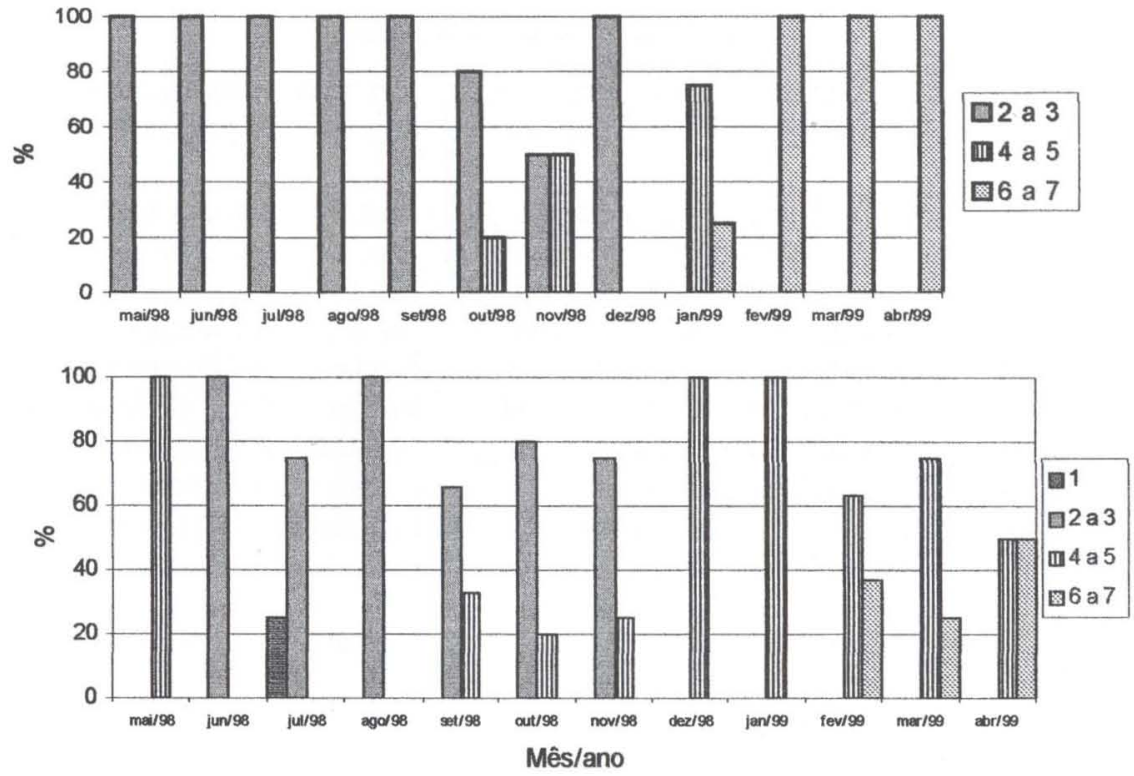

Figs 1-2. Percentagens dos diferentes estádios gonadais em (1) fêmeas e (2) machos de Iphigenia brasiliana.

Tabela II. Medição de estádios avançados de oócitos de Iphigenia brasiliana.

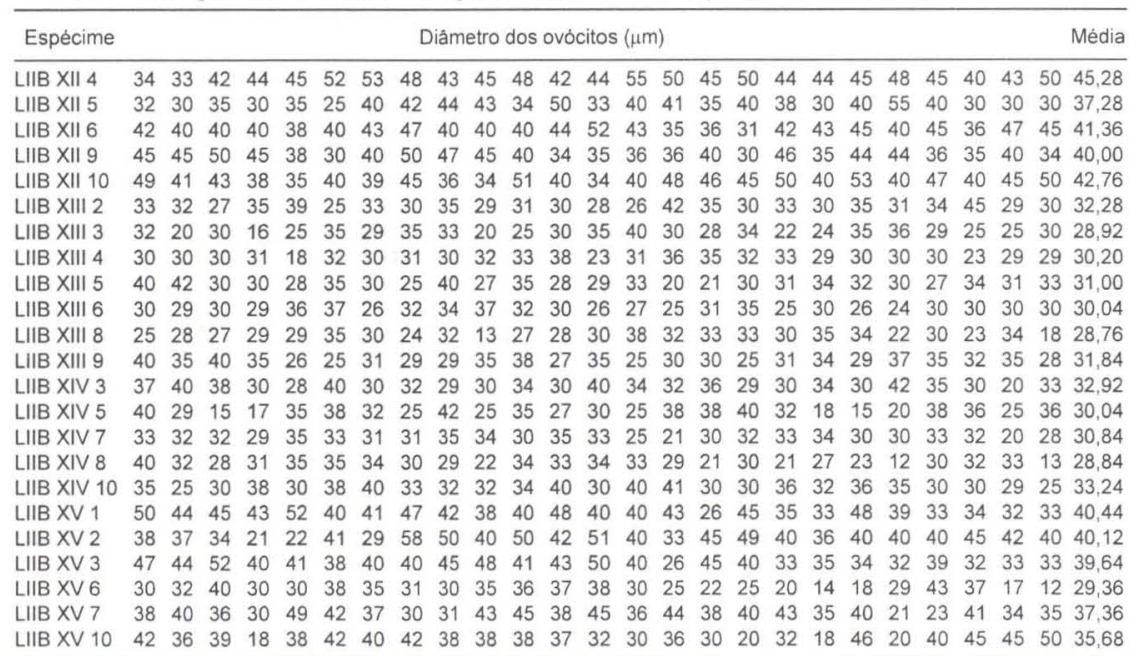

(*) Média total 34,70435; Desvio padrão 5,1958. 


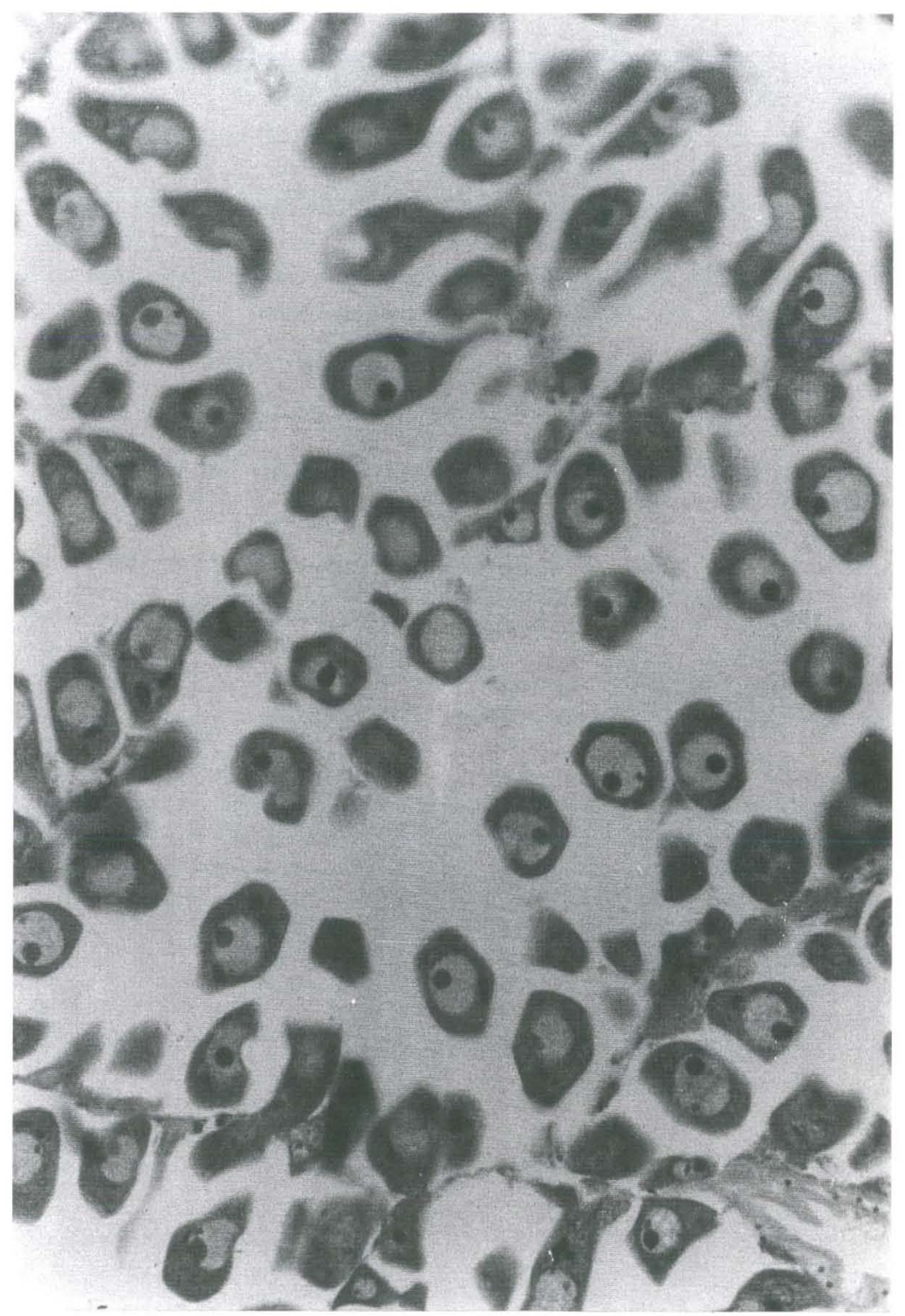

Fig. 3. Fotomicrografia de corte transversal da gônada feminina de Iphigenia brasiliana no estádio 7. Notar os espaços vazios entre os oócitos, caracterizando a gônada desovada. Coloração: HE.

O tecido epitelial do manto mostrou-se PAS positivo demonstrando a presença de células mucíparas produtoras de mucopolissacarídeos neutros. A membrana basal do epitélio do trato digestivo apresentou-se DPAS positiva demonstrando a presença de glicogênio. Pelo van Gieson foi possível observar a disposição do tecido conjuntivo e do tecido muscular, notando-se que os exemplares da espécie $I$. 
brasiliana apresentavam maior quantidade de tecido muscular e menor quantidade de tecido conjuntivo. Pelo Giemsa nada foi evidenciado.

Iphigenia brasiliana é referida como dulciaquíícola por PURCHON (1963), enquanto que THIELE (1935) a observou em águas estuarinas. NARCHI (1972) a encontrou sempre em praias e estuários. No atual estudo, os espécimes foram encontrados em ambientes salinos, aparentemente com perfeita adaptação ao habitat, não apresentando nenhum tipo de patologia detectável, além de ótimo estado de carne, isto é, com bom rendimento das partes comestíveis.

\section{REFERÊNCIAS BIBLIOGRÁFICAS}

Boffl, A.V. 1979. Moluscos brasileiros de interesse médico e econômico. São Paulo, Ed. Hucitec, $182 \mathrm{p}$.

CoE, W.R. 1943. Sexual differentiation in Mollusks. Quart. Jour. Rev. Biol. 18 (2): 154-164.

GOFFERJÉ, C.N. 1950. Contribuição à zoogeografia da malacofauna do litoral do Estado do Paraná. Arq.

Mus. Paranaense, Curitiba, 8: 221-282.

Howard, D.W. \& C.S. SMITH. 1983. Histological Techniques for Marine Bivalve Mollusks. Massachusetts, NOAA Technical Memorandum NMFS-F/NEC-25, 97p.

Lange de Morretes, F. 1949. Ensaio de catálogo dos moluscos do Brasil. Arq. Mus. Paranaense, Curitiba, 7: 5-216.

NARCHI, W. 1972. Comparative study of the functional morphology of Anomalocardia brasiliana (Gmelin, 1791) and Tivela mactroides (Born, 1778) (Bivalvia, Veneridae). Bull. Mar. Sci. 22 (3): 643-670.

1976. A importância do conhecimento dos ciclos gametogênicos de bivalves comestíveis. Seminários de Biologia Marinha. São Paulo, 09 a 15 de dezembro de 1975. An. Acad. Brasil. Ciênc. 47 (Supl.): 133-134.

Powell, E.N.; E.A. Wilson-ORmond \& K.-S. Chol. 1993. Gonadal Analysis - Crassostrea virginica. NOAA Technical Memorandum NOS ORCA 71 National Status and Trends Program for Marine Environmental Quality. Comprehensive Descriptions of Complementary Measurements. Vol 2, p. II.55-II.61.

PURCHON, R.D. 1963. A note on biology of Eigeria radiata Lam. (Bivalvia, Donacidae). Proc. Malacol. Soc. London 35: 251-271.

THIELE, J. 1935. Handbüch der Systematische Weichthierkunde 3. Jena, Gustav Fischer, 778p.

Recebido em 02.03.2000; aceito em 30.V.2001. 